\title{
Precipitation and "Sensitization" of Type 304L Stainless Steel: Correlation of the ASTM A262 Practice A Test with Analytical Electron Microscopy
}

\author{
B. D. Miller and M. G. Burke
}

Bechtel Marine Propulsion Corporation, Bettis Laboratory, PO Box 79, West Mifflin, PA 15122

Cr-rich intergranular (IG) precipitates, generally $\mathrm{M}_{23} \mathrm{C}_{6}$ carbides, form in Type 304/304L austenitic stainless steels during thermal treatment in the temperature range from $\sim 500$ to $900^{\circ} \mathrm{C}$. During precipitation, the level of $\mathrm{Cr}$ at the grain boundaries and adjacent to the carbides may decrease, depending on the aging temperature. If the $\mathrm{Cr}$ content decreases to $<\sim 12 \mathrm{wt} \%$, the grain boundaries are considered "sensitized" and susceptible to intergranular attack. Frequently, the ASTM A262 Practice A test method, which involves an electrolytic etch using dilute oxalic acid for 90 seconds with a current of $1 \mathrm{~A} / \mathrm{cm}^{2}$ [1], is used for determining susceptibility to IG attack. These etch conditions are known to preferentially attack $\mathrm{Cr}$ carbides [2] and leave a "dual" or "ditched" grain boundary structure that is visible using optical microscopy; in the absence of Cr carbides, the grain boundaries are "stepped". The Practice A standard requires that materials exhibiting the "ditched" structure undergo the ASTM A262 Practice E test; however, grain boundary $\mathrm{Cr}$ depletion has been inferred based solely on the Practice A results (for example, [3]).

In this study, as-received Type 304L stainless steel containing 18 ppm boron exhibited a "dual" grain boundary structure following the Practice A test even though the alloy had a low carbon content $(\sim 0.02 \mathrm{wt} . \%)$. Detailed microstructural characterization utilizing analytical electron microscopy (AEM) coupled with laboratory solution-anneal $\left(\sim 1080^{\circ} \mathrm{C} / 30 \mathrm{~min}+\right.$ waterquench(WQ)), sensitization $\left(700^{\circ} \mathrm{C} / 2 \mathrm{hrs}+\mathrm{WQ}\right)$ and stabilization $\left(900^{\circ} \mathrm{C} / 2 \mathrm{hrs}+\mathrm{WQ}\right)$ heat treatments were performed to assess the precipitation behavior in this steel. The sensitization and stabilization heat treatments were chosen to nucleate IG precipitates with concomitant $\mathrm{Cr}$ depleted regions and nucleate IG precipitates with reduced grain boundary $\mathrm{Cr}$ content, respectively. Following the Practice A etch, the laboratory solution-annealed material exhibited a "stepped" boundary structure while both the sensitized and stabilized materials, presented in Figure 1, were strongly "ditched".

Intergranular, Cr-rich $\mathrm{M}_{2} \mathrm{~B}$-type borides, identified by electron diffraction, were detected in the as-received, laboratory solution-annealed, and aged conditions. Semi-quantitative measurements of grain boundary $\mathrm{Cr}$ content using energy dispersive x-ray spectroscopy (EDXS), examples are presented in Figure 2, revealed $\mathrm{Cr}$ levels from 15 - 17 wt.\% in the mill solution-annealed material, with Cr-depleted zones ranging from $10-40 \mathrm{~nm}$ in extent. Isolated IG borides were observed in the laboratory solution-annealed material and the grain boundary $\mathrm{Cr}$ content was comparable to that in the surrounding grains (18 - $19 \mathrm{wt} . \%)$. In contrast, samples aged at $700^{\circ} \mathrm{C}$ ("sensitized") exhibited Cr levels in excess of $14 \mathrm{wt} . \%$ and concomitant Cr-depleted zones less than $50 \mathrm{~nm}$ in extent. Interestingly, despite exhibiting fully "ditched" grain boundaries, Cr levels of $\sim 18-20 \mathrm{wt} . \% \mathrm{Cr}$ with no Cr-depleted zones were detected in specimens aged at $900^{\circ} \mathrm{C}$ (i.e.,"stabilized"). These results establish that the ASTM A262 Practice A test preferentially attacks Cr-rich IG borides in the absence of a Cr-depleted zone. As such, the Practice A test method can yield a "false-positive" indication of IG susceptibility and should not be solely used to infer grain boundary $\mathrm{Cr}$-depletion. 


\section{References}

[1] 2007 Annual Book of ASTM standards, Vol. 1.03

[2] M.A. Streicher, J. Electrochemical Soc. 106 (1959) 161-180.

[3] S.C. Bali, et al. Corrosion. 65 (2009) 726-740.

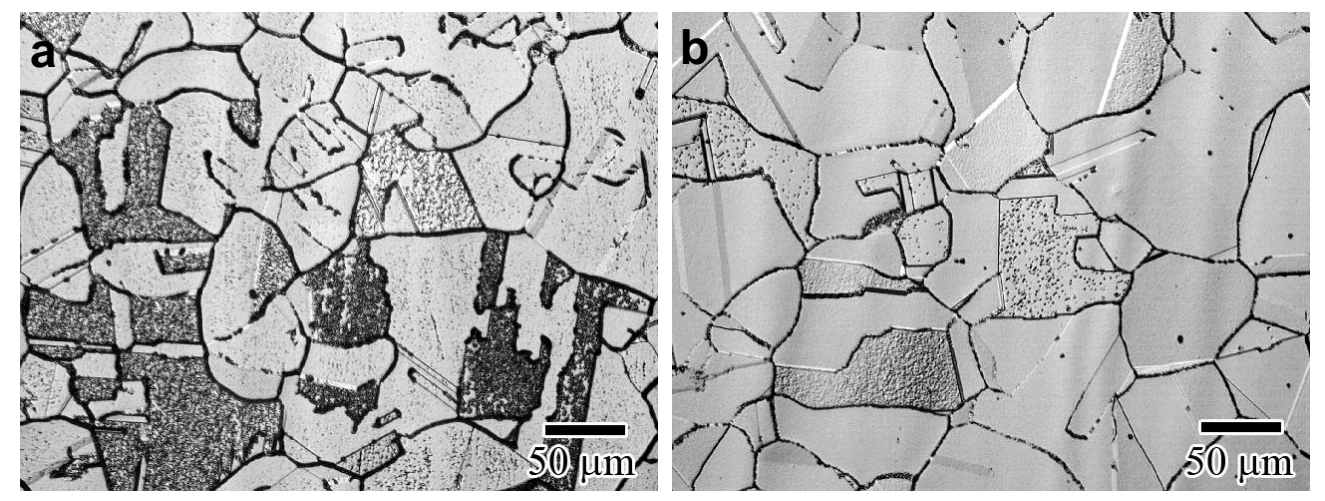

Figure 1. Optical micrographs following the ASTM A262 Practice A test showing "ditched" grain boundaries in both (a) "sensitized" and (b) "stabilized" Type 304L stainless steel.
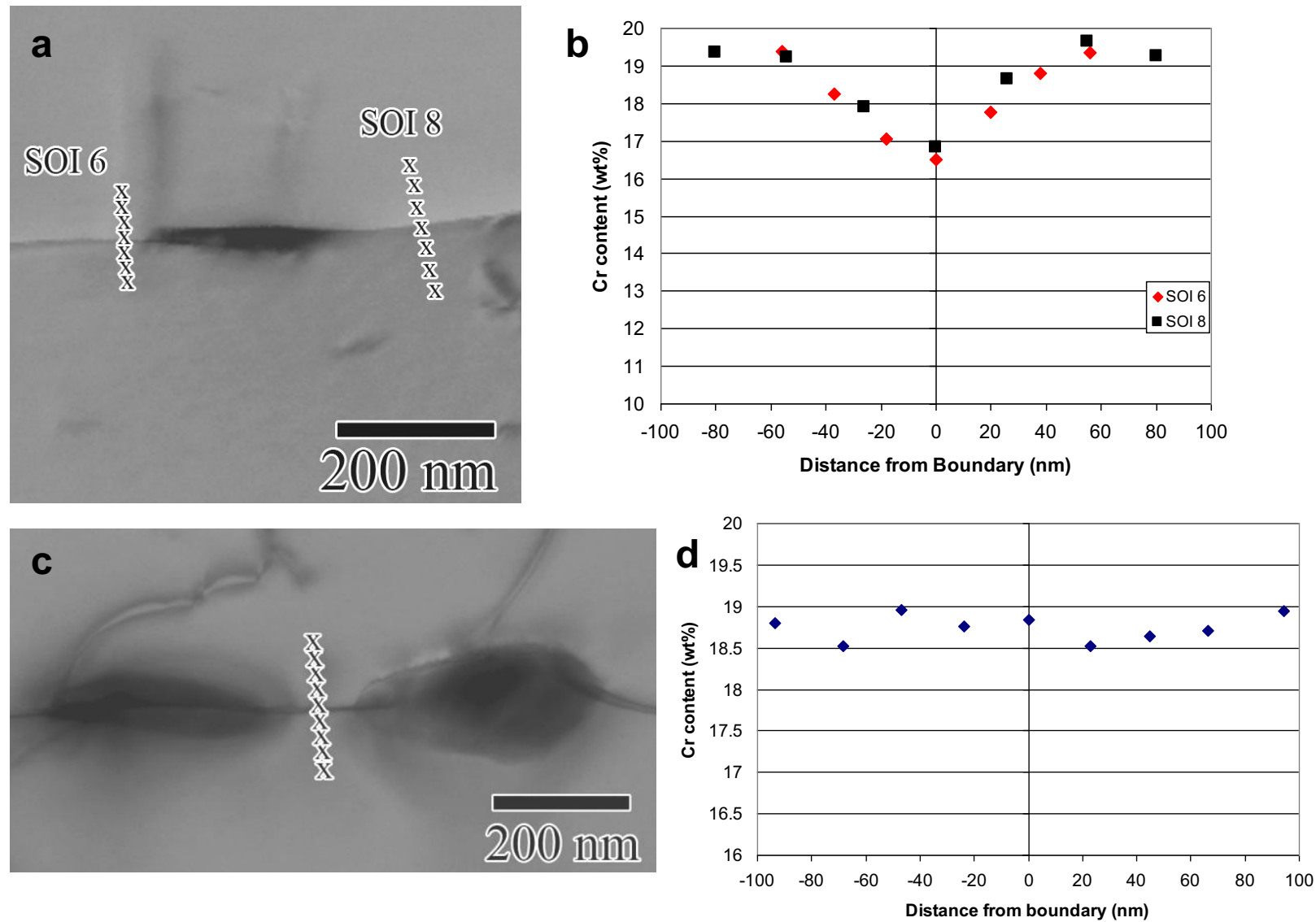

Figure 2. Bright Field-Scanning Transmission Electron Microscopy (STEM) images and associated STEM-EDXS grain boundary Cr concentration profiles for (a), (b) "sensitized" and (c), (d) "stabilized" Type 304L stainless steel. 